\title{
MAJOR DEPRESSION AMONG PREGNANT MOTHERS WITH HIV: CORRELATES AND SUGGESTED INTERVENTIONS
}

\section{E Thiruvalluvan}

\begin{abstract}
Introduction: Psychological disturbance particularly depression is common among people living with HIV infection. More so among pregnant mothers due to concerns with regard to safe delivery, transmission of HIV infection to child, worries about the future and so on. Therefore, this study was undertaken to explore and describe the prevalence and correlates of depression in order to plan an appropriate intervention to ensure quality of life to women with HIV and their children.
\end{abstract}

Methodology: Antenatal mothers with HIV infection who attended Department of Obstetrics and Gynecology, Government Rajaji Hospital, Madurai between December 2007 and September 2008 for parturition were included in the study. Depression was assessed using the center for epidemiology studies depression scale (CES-D). The scale has 20 items, with a 4 point Likert scale scores ranging from 0-3 for each statement.

Results: A total of 53 respondents were included in the study. Median age of the respondents was 25 years. Despite availability of services of Voluntary Counselling and Testing Centre (VCTC) only 34 respondents underwent HIV screening Depression score. One tenth of them have experienced major depression. Sixteen respondents were depressed on knowing their HIV status, 22 respondents were shocked on receiving of positive results while six respondents attempted to commit suicide. Feeling of discrimination ( $\mathrm{p}-0.003)$ and thought of abortion after knowing the HIV positive status ( $\mathrm{p}-.003)$ had significant influence in experience of major depression.

Conclusion: Quality of services of counsellors at antenatal clinics need to be improved and encouraged to periodically assess the psychological needs of antenatal / pregnant mothers. Sensitizing women on methods of family planning should begin during pregnancy and in the post natal period. Referral services should be strengthened further for timely intervention.

Key words: HIV Infected Pregnant Mothers, Depression, and Intervention Strategy

\section{INTRODUCTION}

Parent-to-child transmission of HIV accounts for $2.14 \%$ of the total HIV infection load in India. Estimates in the year 2006 suggested that national adult HIV prevalence was approximately 0.36 per cent, amounting to 2.34 million (ranging between 2 and 3.1 million) people living with HIV and AIDS. ${ }^{1}$ Whereas, HIV prevalence among antenatal clinic (ANC) population had wide variation between

\section{Correspondence:}

Dr. E. Thiruvalluvan PhD.

40/15, Vignesh Avenue 2nd street

Karupayurani, Madurai - 625020

India

Email: e.thiru@gmail.com states. HIV prevalence among antenatal women slightly increased from $1.25 \%$ in 2003 to $1.26 \%$ in the year 2006 in the state of Andhra Pradesh (AP); while in Tamilnadu the prevalence rate came down from $0.50 \%$ to $0.25 \%$ during the same period. ${ }^{2}$

From the psycho social perspective people living with HIV infection particularly women, face a multitude of problems, particularly depression is very common among people living with HIV infection. ${ }^{3,4}$ Commonly observed psycho social problems ranged from self inhibition to social discrimination. Self inhibition is closely associated with fear of death and perceived social stigma rather than enacted stigma. Psychological disturbances arising out of fear of death, has serious repercussion on the quality of life of people living with HIV. Antenatal mothers found 
to be infected with HIV are particularly vulnerable as they face the twin challenge of self and the unknown status of their children to be born. In spite of HIV infection decision to give birth is influenced by particularly social pressure in many societies. Irrespective of the choice, whether personal choice or forced, mere presence of HIV infection itself is likely to generate anxiety in a woman. Anxiety could be with regard to safe delivery, transmission of HIV infection to child, worries about the future and so on. Disclosure of HIV status continues to be a major barrier for emotional well being to an HIV positive individual. Studies reported that perceived ${ }^{5}$ stress was associated with disclosure and access and availability of social support on disclosure.

Poorer family cohesion was also observed ${ }^{6}$ owing to elevated depression that results in poorer family sociability. Depression also was associated with the mothers being less able to perform routine tasks that they typically do; hence children of more depressed mothers had increased responsibilities for household tasks. According to Murphy ${ }^{7}$ et al, $51 \%$ of the mothers with HIV infection met DSMIV diagnostic criteria for a psychological disorder in the preceding year. Posttraumatic stress disorder and major depression ${ }^{8-9}$ are the most commonly diagnosed psychological disorders among women with HIV infection.

High depression scores were associated with women who were no longer in a relationship with their partner, whose babies were HIV-infected, who had not disclosed their HIV status to others and who reported that their HIV-infection was something about which their family would be ashamed of. Hence, it is important to remember that ${ }^{10}$ in spite of added social support and medical treatments, HIV-positive women tend to show higher levels of health care discrimination, personal isolation, and psychological sequel than their sero-negative counterparts. Hence, an assessment of presence of major depression in HIV infected mothers was needed to get a clear picture of the prevalence and correlates of depression in order to plan and initiate appropriate intervention to ensure better quality of life to both women and their children.

The present study made an attempt to assess the prevalence of major depression experienced by antenatal HIV positive women in Madurai South India where HIV disproportionately affects the poor and disadvantaged, adding to the burden on the affected people as well as the health care system.

\section{METHODOLOGY}

\section{Setting:}

The study was carried out in Government Rajaji Hospital, Madurai. Fifty three HIV infected women who delivered a baby between December 2007 and September 2008, were included in the study. Informed consent was obtained prior to administering the interview schedule. The study was approved by the Institutional Ethics Committee and was part of a larger study following HIV infected women and their infants up to 24 months.

\section{Data collection:}

A semi structured interview schedule was developed for data collection. The interview schedule contained details on socio economic profile, history of health seeking, HIV screening, disclosure and reactions to knowing their HIV status and that of their children, whether drugs to prevent HIV transmission had been taken, feeding choices and reasons for the feeding choice .

Depression was assessed using the CES-D scale. ${ }^{11}$ The centre for epidemiology studies depression scale is a widely used 20 item scale that examines the severity of depression. This 4 point Likert scale has scores ranging from 0-3 for each statement. Depression rating is based on the scores as follow:

1. score 22 or more - Major depression

2. Score 15-21- Mild to moderate depression

3. Score less than 15 - No depression.

The scale has been used in India, validated with internal consistency.

\section{Data analysis:}

The data was entered in and analyzed using SPSS-11 statistical software, frequency tables, cross tabulations were prepared after data coding and cleaning. Levene's Independent sample test was performed to observe the association between various independent variables and experience of major depression.

\section{RESULTS}

A total of 53 respondents were included in the study. Socio-demographic details such as age, education, occupation, income, husband's education etc., are given in Table 1. Median age of the respondents 
was 25 years. Half of the respondents were above the age of 25 years. Minimum age of the respondents was 20 and the maximum of 35 years. Median age of the spouses was 30 years with the range between 25 years and 46 years.

Two third of the respondents were illiterate. Less than one tenth of respondents had secondary level education. Similarly, one third of spouses were illiterate. Close to $90 \%$ of the respondents were daily wage earners and remaining were housewives. Half of the respondents had monthly income of less than US $\$ 30$. Mean family income was INR 2248.98 (SD 1862.4) with the range of INR 500-10000. Forty one percent reported it was their first delivery after seroposivity. Close to half of the respondents came for $2^{\text {nd }}$ delivery. One tenth respondents reported for $3^{\text {rd }}$ or successive deliveries.

\begin{tabular}{|c|l|c|c|}
\hline \multirow{2}{*}{ Table 1. Socio demographic profile of the study participants } \\
\hline Variables & \multicolumn{1}{|c|}{ Sub-variables } & $\mathbf{N}$ & $\%$ \\
\hline \multirow{4}{*}{ Age(years) } & $<25$ years & 27 & $50.9 \%$ \\
\cline { 2 - 4 } & 25 or more & 26 & $49.1 \%$ \\
\cline { 2 - 4 } & Total & 53 & $100.0 \%$ \\
\cline { 2 - 4 } & Median age & \multicolumn{2}{|c|}{25} \\
\cline { 2 - 4 } & Standard deviation & \multicolumn{2}{|c|}{3.114} \\
\hline Education & Illiterate & 17 & $32.1 \%$ \\
\cline { 2 - 4 } & Primary education & 9 & $17.0 \%$ \\
\cline { 2 - 4 } & Middle school & 17 & $32.1 \%$ \\
\cline { 2 - 4 } & Secondary $\&$ above & 10 & $18.9 \%$ \\
\cline { 2 - 4 } & Total & 53 & $100.0 \%$ \\
\hline \multirow{5}{*}{ Occupation } & Daily wage & 45 & $84.9 \%$ \\
\cline { 2 - 4 } & House wife & 8 & $15.1 \%$ \\
\cline { 2 - 4 } & Total & 53 & $100.0 \%$ \\
\hline \multirow{5}{*}{ Income } & Less than 1500 & 31 & $58.5 \%$ \\
\cline { 2 - 4 } & More than 1500 & 22 & $41.5 \%$ \\
\cline { 2 - 4 } & Total & 53 & $100.0 \%$ \\
\hline \multirow{5}{*}{ Order of birth } & First child & 21 & $41.2 \%$ \\
\cline { 2 - 4 } & Second child & 24 & $47.1 \%$ \\
\hline & Third or more & 8 & $11.8 \%$ \\
\cline { 2 - 4 } & Total & 53 & $100.0 \%$ \\
\hline
\end{tabular}

\section{HIV profile:}

Details pertaining to HIV screening, such as reason for HIV screening, reactions to HIV positive results, history of HIV in the family screening etc, (Table - 2 ) were available only for 52 . Voluntary Counseling and Testing Centre (VCTC) services are made available at the public hospitals across the state of Tamilnadu, India and all pregnant women are encouraged to undergo HIV screening during pregnancy. In spite of this just one third of

\begin{tabular}{|c|c|c|c|}
\hline Variables & Sub-variables & No & $\%$ \\
\hline \multirow{7}{*}{$\begin{array}{l}\text { Reason for } \\
\text { HIV } \\
\text { Screening }\end{array}$} & During pregnancy & 34 & 64.15 \\
\hline & After Delivery & 3 & 5.6 \\
\hline & Owing to husband's status & 6 & 11.3 \\
\hline & Self sickness & 4 & 7.54 \\
\hline & Owing to child's ill health & 5 & 9.43 \\
\hline & Unknown & 1 & 1.89 \\
\hline & Total & 53 & 100.00 \\
\hline \multirow{5}{*}{$\begin{array}{l}\text { HIV Status } \\
\text { Disclosed by }\end{array}$} & Counselor & 36 & 67.92 \\
\hline & Doctor & 12 & 22.64 \\
\hline & \begin{tabular}{|l|} 
NGO/Nurses/Hospital workers \\
\end{tabular} & 4 & 7.55 \\
\hline & \begin{tabular}{|l|} 
Unknown \\
\end{tabular} & 1 & 1.89 \\
\hline & Total & 53 & $100.0 \%$ \\
\hline \multirow{8}{*}{$\begin{array}{l}\text { Reaction to } \\
\text { HIV Status }\end{array}$} & None & 6 & 11.32 \\
\hline & Suicide attempt & 6 & 11.32 \\
\hline & Shocked & 18 & 33.96 \\
\hline & Depressed & 16 & 30.19 \\
\hline & Fear & 3 & 5.6 \\
\hline & Could not accept & 1 & 1.89 \\
\hline & Unknown & 3 & 5.66 \\
\hline & Total & 53 & 100.00 \\
\hline \multirow{5}{*}{$\begin{array}{l}\text { Kind of } \\
\text { Service to } \\
\text { Need }\end{array}$} & \begin{tabular}{|l|} 
None \\
\end{tabular} & 33 & 62.26 \\
\hline & Govt. Hospital & 11 & 20.75 \\
\hline & \begin{tabular}{|l|} 
Private \\
\end{tabular} & 7 & 13.22 \\
\hline & Unknown & 2 & 3.77 \\
\hline & Total & 53 & 100 \\
\hline \multirow{4}{*}{$\begin{array}{l}\text { Discriminated } \\
\text { Feeling }\end{array}$} & Yes & 7 & 13.22 \\
\hline & \begin{tabular}{|l|} 
No \\
\end{tabular} & 44 & 83.02 \\
\hline & \begin{tabular}{|l|} 
Unknown \\
\end{tabular} & 2 & 3.77 \\
\hline & Total & 53 & 100 \\
\hline \multirow{4}{*}{ Birth Weight } & Less than $2.6 \mathrm{Kg}$ & 22 & 41.51 \\
\hline & $2.6 \mathrm{Kg} \&$ above & 28 & 52.83 \\
\hline & Unknown & 3 & 5.66 \\
\hline & Total & 53 & 0.01 \\
\hline \multirow{4}{*}{$\begin{array}{l}\text { Neonatal } \\
\text { Status }\end{array}$} & Full term & 48 & 90.56 \\
\hline & \begin{tabular}{|l|} 
Premature \\
\end{tabular} & 3 & 5.66 \\
\hline & \begin{tabular}{|l|} 
Unknown \\
\end{tabular} & 2 & 3.77 \\
\hline & Total & 53 & 100 \\
\hline \multirow{4}{*}{$\begin{array}{l}\text { ARV to } \\
\text { Mother }\end{array}$} & Yes & 37 & 69.81 \\
\hline & \begin{tabular}{|l|} 
No \\
\end{tabular} & 13 & 24.52 \\
\hline & Unknown & 3 & 5.66 \\
\hline & Total & 50 & 100 \\
\hline \multirow{4}{*}{$\begin{array}{l}\text { ARV to } \\
\text { Newborn }\end{array}$} & Yes & 39 & 73.58 \\
\hline & \begin{tabular}{|l|} 
No \\
\end{tabular} & 11 & 20.75 \\
\hline & Unknown & 3 & 5.66 \\
\hline & Total & 53 & 100 \\
\hline \multirow{5}{*}{$\begin{array}{l}\text { Type of } \\
\text { Feeding }\end{array}$} & Breast feeding & 20 & 37.73 \\
\hline & Bottle feeding & 14 & 26.41 \\
\hline & Mixed & 17 & 32.07 \\
\hline & Unknown & 2 & 3.77 \\
\hline & Total & 53 & 100 \\
\hline \multirow{7}{*}{$\begin{array}{l}\text { Feeding } \\
\text { Choice }\end{array}$} & Money & 7 & 13.20 \\
\hline & Taboo & 1 & 1.88 \\
\hline & On Medical advise & 38 & 71.69 \\
\hline & \begin{tabular}{|l|} 
Emotion \\
\end{tabular} & 2 & 3.77 \\
\hline & \begin{tabular}{|l|} 
Others \\
\end{tabular} & 2 & 3.77 \\
\hline & Unknown & 3 & 5.66 \\
\hline & Total & 53 & 100 \\
\hline
\end{tabular}


respondents underwent HIV screening. One tenth of the respondents sought HIV screening only when their children fell sick. One third of respondents were depressed on knowing their HIV status while one tenth of respondents attempted to commit suicide. Thirty six percent of respondents were shocked on receiving of positive results. Close to one third of respondents received their HIV results form from a counselor. One fourth of respondents received information from doctors, One tenth of respondents felt they were discriminated because of their HIV status. Due to delay in HIV screening one fourth of respondents and their children did not receive ARV to prevent mother to child transmission of HIV.

Premature death of the infant was reported by $5.9 \%$ of the respondents while $44 \%$ had low birth weight infants. Type of feeding practice had an equal mix. Breast feeding was opted by $39 \%$ of mothers and bottle feeding was reported by one fourth of mothers. In majority of the respondents $(76 \%)$, type of feeding was decided basing on medical advice. One tenth of respondents reported money was the reasons for their choice of feeding.

\section{Depression among mothers:}

Presence of depression associated with various socio-demographic and clinical aspects are presented in Table 3. Mild to moderate depression was observed in $17.6 \%$ of the respondents. Eighty two percent of the respondents were observed to be experiencing major depression. Table 4 respondents aged below 25 years reported higher incidence of depression than their elder counterparts. Respondent who were illiterate or had middle school education (31.4\%) reported higher incidence of depression. Daily wage earners were more likely to experience depression due to HIV infection perhaps associated with economic burden. Mothers who reported for $1^{\text {st }}$ and $2^{\text {nd }}$ child birth were more likely to experience major depression. Close to half of the respondents found to be seropositive were delivering the first child. More respondents whose HIV status was disclosed by a counselor reported major depression which highlights the inadequacy in the counseling process. Experience of shock had its impact on the level of depression. Even though fewer respondents reported to have thought of abortion, presence of depression was very high among those who decided to continue with their conception. All those who felt they were discriminated experienced major depression. Respondents who followed their physician's advice on feeding were emotionally disturbed in some or other way, which resulted in higher incidence of major depression. Levene's Test for Equality of Variances was performed on key independent variables with depression score to see whether or not they were interdependent. Feeling of discrimination (p-0.003) and thought of abortion after knowing the HIV positive status ( $p$ .003) had significant influence in reporting of major depression. Income status of the respondents (p-.090) had some influence in the experience of depression though it was statistically not significant.

\begin{tabular}{|c|c|c|c|c|c|c|c|}
\hline \multicolumn{8}{|c|}{$\begin{array}{l}\text { Table 3. Depression in relation to socio demographic } \\
\text { characteristics }\end{array}$} \\
\hline \multirow[t]{2}{*}{ Variables } & \multirow[t]{2}{*}{$\begin{array}{l}\text { Sub- } \\
\text { vari- } \\
\text { ables }\end{array}$} & \multirow{2}{*}{\begin{tabular}{|c} 
Mild to \\
mode- \\
rate \\
depre- \\
ssion \\
Count
\end{tabular}} & \multirow{2}{*}{\begin{tabular}{|l|}
$\begin{array}{l}\text { Major } \\
\text { depre- } \\
\text { ssion }\end{array}$ \\
Count \\
\end{tabular}} & \multicolumn{2}{|c|}{ 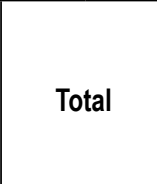 } & \multicolumn{2}{|c|}{\begin{tabular}{|c|} 
Levene's \\
Test for \\
Equality of \\
Variances
\end{tabular}} \\
\hline & & & & Count & $\%$ & $F$ & $\begin{array}{c}\text { P. } \\
\text { value }\end{array}$ \\
\hline \multirow{4}{*}{ Income } & $\begin{array}{c}\text { Less } \\
\text { than INR } \\
1500 \\
\end{array}$ & 6 & 23 & 29 & 54.72 & \multirow{4}{*}{2.986} & \multirow{4}{*}{.090} \\
\hline & $\begin{array}{c}\text { More } \\
\text { than INR } \\
1500\end{array}$ & 3 & 19 & 22 & 41.51 & & \\
\hline & Unknown & 2 & & 2 & 3.77 & & \\
\hline & Total & 11 & 42 & 53 & 100 & & \\
\hline \multirow{4}{*}{$\begin{array}{l}\text { Thought } \\
\text { of Abor- } \\
\text { tion }\end{array}$} & Yes & 3 & 4 & 7 & 13.21 & \multirow{4}{*}{9.962} & \multirow{4}{*}{.003} \\
\hline & No & 6 & 37 & 43 & 81.13 & & \\
\hline & Unknown & 3 & & 3 & 5.66 & & \\
\hline & Total & 9 & 41 & 50 & 100 & & \\
\hline \multirow{4}{*}{$\begin{array}{c}\text { Dis- } \\
\text { criminated } \\
\text { Feeling }\end{array}$} & Yes & 0 & 7 & 7 & 13.21 & \multirow{4}{*}{9.600} & \multirow{4}{*}{.003} \\
\hline & No & 8 & 35 & 43 & 81.13 & & \\
\hline & Unknown & 3 & & 3 & 5.66 & & \\
\hline & \begin{tabular}{|l|} 
Total \\
\end{tabular} & 8 & 42 & 50 & 100 & & \\
\hline
\end{tabular}

Table 4. Depression among Expectant mothers

\begin{tabular}{|l|c|c|}
\hline \multicolumn{1}{|c|}{ Depression status } & $\mathbf{n}$ & $\%$ \\
\hline No depression & 2 & 3.8 \\
\hline Mild to moderate depression & 9 & 17.0 \\
\hline Major depression & 42 & 79.2 \\
\hline
\end{tabular}

\section{DISCUSSION}

This study has clearly shown that HIV causes major depression in HIV infected antenatal mothers. Experience of major depression was directly related to illiteracy, type of occupation, age and lower income status. In terms of order of birth, half of the respondents became pregnant for the second time in spite of knowing the chances of mother to child transmission of HIV. Such contraction requires immediate attention from the 
health care providers and AIDS workers. This gap may be due to absence of effective intervention at the health setup or may be due to attitude of the women themselves. Forty four percent of children born to HIV infected mothers were low birth weight babies .Psychological disturbances i.e. experience of major depression coupled with poor socioeconomic conditions could have impacted this.

Breast feeding was opted by $39.2 \%$ of respondents despite knowing the risk of mother to child transmission. Economic determinants coupled with cultural factors could have determined the choice of feeding. Though the study did not look at the cultural reasons, it was evident that the participants economical status did have a major role in the choice of feeding as close to one third of the respondents had income below INR 1500.

Discrimination owing to HIV status is still high among the participants. Participants who felt discriminated were more likely to experience major depression. Discrimination may include a broad range of harmful actions against individuals who are known or suspected of having HIV or AIDS (and/or their families), including rejection, exclusion from social or ritual events, gossip, ridicule, verbal harassment, abandonment, divorce, expulsion from their homes, removal of economic support, denial of property and, in some cases, physical violence. ${ }^{12}$ Likewise participants in this study who felt discriminated have experienced major depression.

Secondly the impact of disclosure also needs a close considering while trying to address the psychological disturbances among women. The negative consequences of disclosure are more frequently documented for women, and several studies show that it is among pregnant women that fears of abuse as a possible consequence of testing positive for $\mathrm{HIV}^{13}$ manifest more. This was observed among the respondents too as one third of women were asked to stay away from husband's place. Furthermore, increase in incidence of $2^{\text {nd }}$ pregnancy highlights the need for an appropriate, relevant and effective intervention package in the post natal period. First one is promotion of planned deliveries.

\section{Promotion of planned deliveries}

Increased incidence of $2{ }^{\text {nd }}$ pregnancy highlights the absence of unplanned pregnancy among the study community. In addressing the issue one, health care workers should provide necessary education, counseling and services on prevention of unwanted pregnancy. Presently, family planning program just looks at the number that could be achieved through permanent contraceptive measures. Permanent contraceptive methods are not yet popular among Indian women and it is considered as a right choice for women who are old enough not to give birth. Secondly, emergency contraceptives are not yet given enough attention. In addressing this issue, health care workers should develop culturally appropriate family planning methods.

\section{Counseling and peer support groups}

Counselling has been used to resolve issues with family and community members and to teach coping skills. Interventions studies suggest that counselling may reduce anxiety and distress, reduce negative consequences of disclosure and improve attitudes towards people living with HIV. ${ }^{14}$ Counselling and "mediated disclosure" can be used to help clients who test positive for HIV consider how to disclose their status to partners and others in a way that reduces risks to their physical safety and emotional wellbeing. ${ }^{15}$ As for as the quality of counselling services, women's experiencing major depression was high in spite of the counselling services that they received from a counsellor. This clearly shows that there is inadequacy in the services provided by the counsellors. Currently, the quality of counselling services provided to the ANC mothers is not reported to be effective. Therefore, the counsellors should improve their quality of services that address the psychological needs of women. Counsellors should also be trained on various psychotherapeutic methods and tools.

Peer support groups have also been shown to benefit people living with HIV in terms of selfesteem, coping skills and social integration ${ }^{16}$ in a few situations. Therefore the researchers suggest that the counsellors can promote the concept of peer support groups as part of counselling services they offer.

\section{Psychiatric intervention}

Provision of services of a psychiatrist or psychiatric social worker can also be explored so that major depressions among women are identified early to initiate appropriate intervention.

Therefore, the researchers conclude that high level of major depression among ANC mothers needs immediate attention from health care workers. 
Hence, ANC services should include referral mechanism to psychiatric interventions.

Simultaneously attempts should be made to improve the quality of services of counsellors and health care workers attached to HIV screening centers on planned delivery in both private and public health system.

\section{CONCLUSION}

This study finding clearly demonstrates that sizable percentage of pregnant mothers with HIV infection experience major depression. Therefore, quality of services of counsellors at ANC clinic and VCTCs need to be improved. In addition, the counsellors may be encouraged to perform periodical assessment of psychological needs of pregnant mothers. Further a comprehensive service package including referral for mental health services, commencing women on antenatal treatment, diagnosis and treatment of children born to pregnant women should be made available.

\section{REFERRENCES}

1. Gupte N, Sastry J, Brookmeyer R, Phadke MA, Bhosale RA, Bollinger RC; BJ Mother-to-Child Study Group. Declining HIV infection rates among recently married primigravid women in Pune, India1: Journal of Acquir Immune Defic Syndr. 2007 Aug 15;45(5):570-3

2. Cho J, Holditch-Davis D, Miles MS. Effects of maternal depressive symptoms and infant gender on the interactions between mothers and their medically at-risk infants. Journal of Obstet Gynecol Neonatal Nurs. 2008 Jan-Feb;37(1):58-70.

3. Murphy DA, Austin EL, Greenwell L. Correlates of HIV-related stigma among HIV-positive mothers and their uninfected adolescent children. Women Health. 2006;44(3):19-42.

4. Silver EJ, Bauman LJ, Camacho S, Hudis J. Factors associated with psychological distress in urban mothers with late-stage HIVIAIDS. AIDS Behaviour. 2003 Dec;7(4):421-31.

5. Kalichman SC, DiMarco M, Austin J, Luke W, DiFonzo K. Stress, social support, and HIV-status disclosure to family and friends among HIV-positive men and women. Journal of Behav Med. 2003 Aug;26(4):315-32.

6. Murphy DA, Marelich WD, Dello Stritto ME, Swendeman D, Witkin. A Mothers living with HIVI AIDS: mental, physical, and family functioning. AIDS Care. 2002 Oct; 14(5):633-44.
7. Murphy LM, Koranyi K, Crim L, Whited S. Disclosure stress and psychological adjustment among mothers affected by HIVIAIDS Patient Care STDS 1999 Feb;13(2):111-8.

8. Johnson MO, Lobo ML Mother-child interaction in the presence of maternal HIV infection. Journal of Assoc Nurses AIDS Care. 2001 JanFeb;12(1):40-51.

9. Bennetts A, Shaffer N, Manopaiboon C, Chaiyakul P, Siriwasin W, Mock P, Klumthanom K, Sorapipatana S, Yuvasevee C, Jalanchavanapate $S$, Clark L. Determinants of depression and HIVrelated worry among HIV-positive women who have recently given birth, Bangkok, Thailand. Soc Sci Med. 1999 Sep;49(6):737-49.

10. Lester P, Partridge JC, Chesney MA, Cooke M. The consequences of a positive prenatal HIV antibody test for women. Journal of Acquir Immune Defic Syndr Hum Retrovirol. 1995 Nov 1;10(3):341-9.

11. Lenore Sawyer Radloff The CES-D Scale. A Self-Report Depression Scale for Research in the General Population Applied Psychological Measurement June 1977 vol. 1 no. 3 385-401

12. Maman et al. 2006 Maman S, King E, Amin A, et al. (2006) Addressing violence against women in HIV testing and counselling: a meeting report. Geneva: Department of Gender, Women and Health, Department of HIVIAIDS, World Health Organization. Accessed November 2008. Available at: http:// www.who.int / gender / documents/VCT_ addressing_violence.pdf.

13. Manzi et al. Manzi M, Zachariah R, Teck R, et al. High acceptability of voluntary counselling and HIV-testing but unacceptable loss to follow up in a prevention of mother-to-child HIV transmission programme in rural Malawi: scaling-up requires a different way of acting. Tropical Medicine and International Health 2005;10(12):1242-1250.

14. Brown L, Macintyre K, Trujillo L. Interventions to reduce HIVIAIDS stigma: What have we learned? AIDS Education and Prevention. 2003;15:49-69

15. Maman et al. Maman S, King E, Amin A, et al. (2006). Addressing violence against women in HIV testing and counselling: a meeting report. Geneva: Department of Gender, Women and Health, Department of HIVIAIDS, World Health Organization. Accessed November 2008. Available at: http:// www.who.int / gender / documents / VCT_ addressing_violence.pdf.).

16. Heijnders Heijnders M, van der Meij S. The fight against stigma: an overview of stigma-reduction strategies and interventions. Psychology, Health and Medicine 2006;11(3):353-63 